\section{British medicine's desperate need for leadership}

Sir John Tooke and his panel who have been inquiring into Modernising Medical Careers (MMC) are like a team who arrive at the scene of a terrible air crash. ${ }^{1}$ There are bodies, blood, and wreckage everywhere, and the air is filled with rumour, speculation, and blame. How did this awful thing happen and who is at fault? Sir John's panel are doing a thorough job of picking through the wreckage of MMC and the Medical Training Application Service (MTAS), and they are right that this was a 'deeply damaging episode for British Medicine'. Their search has disclosed not only a catalogue of errors but also fundamental problems like there being 'no consensus on the role of doctors at various career stages' and 'an aspiration to mediocrity' not excellence. How could we have gone so wrong? One inevitable conclusion of the panel is that British medicine lacks coherent, strategic, high level leadership - exactly as Sir Maurice Shock warned the profession in $1994 .^{2}$ Instead, we have a plethora of self-interested, ineffective, squabbling bodies. My hope is that out of the wreckage of MMC and MTAS will come the leadership that British medicine desperately needs.

The report quickly dismisses the idea that the disaster was all the fault of the government. It describes the Byzantine advisory structures and makes clear that many medical bodies were involved. Sir John's panel even examined the attendance of representatives of the bodies and shows that they were present when poor decisions were made: 'The question of selection into specialty training was discussed 17 times between 2004 and 2007 in at least three different MMC bodies'. The royal colleges were not, however, adequately consulted on the critical issue of the nature of the MTAS questions and the scoring system employed. Too often, however, advice from the medical organizations was conflicting. Thus the Junior Doctors Committee of the British Medical Association (BMA) argued for a delay in implementation, but after originally supporting a delay the Trainee Doctors Group of the Academy of Medical Royal Colleges withdrew its support-'raising issues about the consistency of medical professional advice on matters of key importance.' The report continues:

Indeed the advice derived from individual medical professional constituencies frequently reflected the particular interests of that grouping rather than the interests of medicine and medical care that the medical profession has frequently failed to proffer coherent advice on key issues of principle, reflecting in part a very complex organizational structure, which owes more to history than necessarily function or purpose. There has been a dearth of medical professional leadership over this period.'

The prescription of the panel is simple: 'The medical profession should have an organization/mechanism that enables coherent advice to be offered on matters affecting the entire profession, including postgraduate medical education and training'. Sir George Godber, who was Chief Medical Officer from 1960 to 1973 and who no doubt received conflicting, self-interested advice from medical organizations, has been making the same point for nearly half a century - unheeded. And it was more than a decade ago at a gathering of all the medical clans that Sir Maurice Shock, former rector of Lincoln College, Oxford, said: 'The doctor is different, the patient is different, and the medicine is different. In short, everything is different except the way you organise yourselves'. ${ }^{2}$ Because doctors lacked a body capable of analysing the environment and setting a strategy for the whole profession, doctors were overwhelmed by a 'blitzkrieg from the right' at the end of the 1980s. To regain their influence, doctors needed a top body concerned primarily with strategic and high political matters. Otherwise, warned Sir Maurice, 'the profession will never be able to punch its weight'.

Sir Maurice also recognized the major barrier to the creation of such a body: 'It almost goes without saying that to achieve action on such a scale will require the leading professional bodies to surrender some of their independence to a new representative body which in its turn would be guided by a cabinet, serviced by a small but first rate administration'. Medical organizations have been reluctant to surrender power and independence, but none of the existing organizations is up to the task - as the MTAS disaster illustrates.

The BMA is the largest and richest of the medical organizations, but it can never be the high-level, strategic body that is needed because - no matter that it may pretend otherwise - it is a self-interested trade union. Whatever it says is discounted. Plus it lacks academic respectability. The royal colleges and specialist societies are like Italy before the Risorgimento, a gallimaufry of city states with limited interests and clout, many of which are politically naive, poor, and incapable of strategic thought. The Academy of Royal Colleges is dysfunctional, and the GMC rightly belongs to patients not doctors and is regulated by Act of Parliament. The Postgraduate Medical Education and Training Board seems to have been almost stillborn and is recommended by Sir John's panel to be swiftly merged with the GMC. So, as the cliché has it, medicine has lots of leaders but no leadership. 
So will the obvious now happen? Will a high level, effective body be formed? Three elements are needed for change: a burning platform ('we can't go on like this or let this happen again'); a vision of what would be better; and clarity on who will do what tomorrow. We certainly have the burning platform, although complacency can break out at any moment in the medical profession. Sir Maurice provided a hasty sketch of what a better organization might look like, and surely Sir John and his panel can in their subsequent work strengthen the vision and provide next steps. Then, as is so often the case in human affairs, disaster will provide the catalyst to something long overdue and very valuable.

Competing interests RS was employed by the BMA for 25 years and is a fellow of various of the colleges.

\section{Richard Smith}

Former editor of the BMJ

London SW4

Email: richardswsmith@yahoo.co.uk

\section{REFERENCES}

1 Independent Inquiry into Modernising Medical Careers. Aspiring to Excellence. London: MMC Inquiry, 2007. Available at http:// www.mmcinquiry.org.uk/draft.htm

2 Shock M. Medicine at the centre of the nation's affairs. BMJ 1994;309 $1730-3$

\section{Emergency admissions- a time for action and improving patient outcomes}

The report Emergency Admissions: A journey in the right direction? was recently published by the National Confidential Enquiry into Patient Outcome and Death (NCEPOD). ${ }^{1}$ This report analysed 1800 medical and surgical patients who were admitted acutely to hospital over seven days in February 2005 and who subsequently died or were transferred to critical care within seven days of admission or died within seven days of discharge. This study, by its nature, analyses the most seriously ill subgroup of patients and, therefore, may underestimate the true extent and nature of problems that may affect care adversely. These include, for example, deficits in care provision that increase the risk of health-care-acquired infection and result in increased length of hospital stay.
The report makes ten principal recommendations which can broadly be divided into issues of competency or process of care-important factors in patient care which have been apparent for many years and were, indeed, highlighted by Hippocrates. In essence, the recommendations state that acutely unwell patients should be seen promptly by a competent clinician, that documentation throughout the patient journey should be accurate and clear, that there should be diagnostic support available 24 hours per day, that patients' physiology should be monitored and that patient transfers should be minimized.

The report highlights that in most of these areas the majority of patients in this severely ill group received adequate care, but in specified areas an unacceptably high proportion received suboptimal care.

How will this report help improve clinical outcomes in acute care? Most, if not all, of the recommendations have been published before in a variety of previous reports. ${ }^{2,3}$ For example, one of the earliest reports, published almost a decade ago, highlighted the need for 24-hour/seven-day per week provision of diagnostic services to support acute medical admissions. ${ }^{2}$ The more recent of these reports ${ }^{3}$ covered all of the NCEPOD recommendations, with the exception of physiological monitoring which has been covered in other reports. ${ }^{4,5}$

The NCEPOD report ${ }^{1}$ highlights that in most of these areas of patient care, progress in implementing the recommendations has been, at best, slow. Before addressing why progress has been slow, we should consider whether the recommendations are themselves sufficient and which areas the report has not covered.

In examining the care delivered in the acute setting, perhaps we should apply the close relative test: what would we as health-care professionals wish to happen for a close relative? The report shows that only $60 \%$ of patients had been seen by a consultant within 12 hours and this was most likely to have occurred within an assessment unit (acute medical or surgical unit) or an inpatient ward. Within 24 hours of admission, $8 \%$ had not been seen. This clearly is not acceptable, especially as the report relates to patients who, by definition, were likely to have poor outcomes. We would argue, however, that even 12 hours is too long to wait for input from a senior professional and that we should aspire to higher standards. How can this be achieved? The current levels of medical manpower would not permit a 24hour consultant presence in the acute setting throughout the UK. We can, however, improve consultant input by working extended hours within the acute units and by ensuring that consultants are informed of all cases of clinical concern. This would require that physiological scoring is implemented uniformly, that we as consultants encourage contact by junior members of staff throughout 24 hours and, as the report reiterates, that job planning must reflect 
the needs of the large number of patients requiring acute care. In relation to early warning scoring systems, it is key that these are linked to clear actions and escalation policies if outcomes are to improve at point of entry to care. ${ }^{6,7}$

Acute medical and acute surgical units must be seen as defined training areas for both undergraduate and postgraduate health-care professionals in order to ensure that competencies relevant to the acute care of patients are achieved. This report covers a large number of areas but predominantly looks at the medical components of care. The delivery of high-quality acute care requires a multiprofessional approach, and the roles of nursing staff and allied health professionals in both detecting and treating acute illness must be recognized and promoted. As such, staffing levels in the acute units and the level of monitoring equipment must also be adequate, ${ }^{8,9}$ but in reality they vary throughout the country. The report does not address these issues, but they are essential for all involved in assessing or redesigning acute services.

The report therefore highlights that much work still requires to be done and essentially reveals that previous national recommendations have not been uniformly adopted.

Why is this the case? The reasons are multifactorial and include that, until recent years, there has been little focus on acute care despite the fact it accounts for the vast majority of both medical and surgical hospital admissions. Other reasons include tensions in prioritization between unscheduled and scheduled care and between acute and specialist care. In addition, many clinicians feel uncomfortable in managing the acutely unwell and this must dictate the need for improved training programmes. Finally, staff are often required to work within systems that are inadequate and poorly organized. This reflects the lack of emphasis on acute care by both health-care professionals and senior managers.

Programmes like the Emergency Services Collaborative and the Unscheduled Care Collaborative have helped emphasize the importance of improving the timeliness and quality of acute care, but this work needs to continue with an even greater emphasis on patient experience and outcomes. ${ }^{10}$ The forthcoming acute medical task force document ${ }^{9}$ re-emphasizes the recommendations of this NCEPOD report but is broader-ranging and takes a more prescriptive, whole-system approach designed to improve the care for all patients requiring acute care. We must now implement the recommendations and ensure that progress is monitored. How can this be done?

First we must recognize that there is wide variation in clinical outcomes for patients in relation to the time and place that they access acute services. ${ }^{11,12}$ This is despite the fact that they may be suffering from similar illness and disease severity. We can do better. Improved care could be delivered at a local level (Trust or Health Board) if it is given the correct emphasis. Or does it require another national programme to coordinate this delivery, with quality and outcomes in acute care as the main focus?

In summary, the NCEPOD report ${ }^{1}$ supports the recommendations of previous reports but perhaps could have gone further, with greater emphasis given to specific components of the recommendations. It does highlight current deficiencies and serves as a useful baseline for the necessary improvement. The importance of the report is that it serves as a timely reminder to us all. However, we must now move into an era of delivery of improved acute care with demonstrable improvement in patient outcomes - in other words it is time for action, not further reports.

Competing interests None declared.

\section{Derek Bell ${ }^{1} \quad$ Mike Jones $^{2}$}

${ }^{1}$ Professor of Acute Medicine, Imperial College, Chelsea and Westminster Campus, London SW10 9NH, UK; ${ }^{2}$ Consultant Physician, Edinburgh Royal Infirmary, Edinburgh EH16 4SA, UK.

Email: d.bell@imperial.ac.uk

\section{REFERENCES}

1 National Confidential Enquiry into Patient Outcome and Death. Emergency Admissions: A journey in the right direction?(2007). London: NCEPOD, 2007. http://www.ncepod.org.uk/2007.htm

2 Acute Medicine Admissions and the Future of General Medicine. Report of a working party. The Royal College of Physicians of Edinburgh, 1998

3 Acute Medicine: making it work for patients. Report of a working party. The Royal College of Physicians of London, 2004. http:// www.rcplondon.ac.uk

4 Emergency Medical Admissions Scoping Group. NHS Quality Improvement Scotland, 2004

5 Acutely Ill Patients in Hospital. Recognition of and response to illness in adults in hospital. NICE Clinical Guideline 50. London: National Institute for Health and Clinical Excellence, 2007

6 Paterson R, MacLeod DC, Thetford D, et al. Prediction of in-hospital mortality and length of stay using an early warning scoring system: clinical audit. Clin Med 2006;6:281-4

7 Hillman KM. Recognising and preventing serious in-hospital adverse events. Med J Aust 1999;171:8-9

8 The Society for Acute Medicine. http://www.acutemedcine.org.uk/ guidelines

9 Acute Medicine Task Force Report . The Royal College of Physcians of London and Society for Acute Medicine (in press)

10 Bell $\mathrm{D}, \mathrm{McNaney} \mathrm{N}$, Jones $\mathrm{M}$. Improving health care through redesign. BMJ 2006;332:1286-7

11 Seward E, Greig E, Preston S, et al. A confidential study of deaths after emergency medical admission: issues relating to quality of care. Clin Med 2003;3:425-34

12 Bell CM, Redelmeier DA. Mortality among patients admitted to hospitals on weekends as compared with weekdays. $N$ Engl $\mathrm{J} \mathrm{Med}$ 2001;345:663-8 